\title{
Managing Equality in Social Dilemmas: Emotional and Retributive Implications
}

\author{
Jeroen Stouten, ${ }^{1}$ David De Cremer, ${ }^{2}$ and Eric van Dijk ${ }^{3}$
}

The equality rule is an important coordination rule in symmetric public good dilemmas. Although prior research emphasized that people use the equality rule out of efficiency concerns (as it helps to obtain the public good in the most efficient manner among group members), it may also reflect a true preference for fairness. More precisely, research examining emotional and retributive reactions as a result of a violation of the equality rule by a fellow group member showed that equality indeed is related to people's personal values and what they consider to be fair. The present paper suggests that a violation of the equality rule results in emotional reactions, and these emotional experiences encourage further retributive actions. The different reactions following an equality violation are described as a function of three features: (1) the motives to use equality, (2) attributions for explaining the violation, and (3) the honesty of the given explanation.

KEY WORDS: equality; social dilemmas; emotions; retribution; distributive justice.

Most public services can only be provided and maintained if sufficient individual contributions have been made. In these situations, there is often a conflict between the personal interest and the collective interest, because it is more profitable to hold on to personal resources and still benefit from the collective good. However, if everyone will choose this option, it is very likely that the necessary means of providing the collective or public good cannot be obtained, which means that all will be worse off than if all would have

\footnotetext{
${ }^{1}$ Department of Psychology, University of Leuven, Tiensestraat 102, 3000 Leuven, Belgium.

${ }^{2}$ Department of Economic and Social Psychology, Tilburg University, Tilburg, The Netherlands.

${ }^{3}$ Social and Organizational Psychology, Leiden University, Leiden, The Netherlands.

${ }^{4}$ Address correspondence to: Jeroen Stouten, Department of Psychology, University of Leuven, Tiensestraat 102, 3000 Leuven, Belgium., e-mail: jeroen.stouten@psy.kuleuven.be
} 
cooperated. Such situations are referred to as step-level public good dilemmas (Dawes, 1980; Komorita and Parks, 1994). In these step-level public good dilemmas individual contributions have to be made in order to reach a certain collective threshold. If the group manages to provide this threshold the public good can be achieved. However, if the threshold cannot be obtained, individual contributions are lost and the public good cannot be achieved.

Research shows that if the public good is obtained, it will be equally divided among all group members (Komorita and Parks, 1994). How will people then regulate their contributions to the public good? If group members receive equal endowments (i.e., a symmetric social dilemma) they are more likely to use the equality rule in making their decisions. This means that people in these symmetric situations commonly contribute an equal share to the public good. Previous theorizing emphasized that people adhere to the equality rule out of efficiency concerns, which means that the rule is easy to use and fits people's instrumental goals (e.g., Allison and Messick, 1990). It has also been argued, however, that people may adhere to equality out of fairness concerns (e.g., Van Dijk and Wilke, 1995). The question remains what the relative importance is of both motives. More precisely, do people use equality because it furthers their own interests or because it is a fundamental issue of fairness and justice. Moreover, it may well be that for some efficiency and for others fairness may be the primary motive for using the equality rule. In the present paper, we will argue that people's emotional reactions may give us more insight into the motives that underlie people's use of the equality rule in social dilemmas. That is, by looking at the valence of the emotions that people display it may become clear whether people use this rule out of efficiency or fairness concerns. Moreover, we will also focus on these emotional experiences, as they may have the potential to subsequently instigate retributive actions. In doing this, the present article will discuss these emotional and retributive reactions in social dilemmas with regard to equality violations by emphasizing the interplay between situational and dispositional factors.

\section{WHY PEOPLE CARE FOR EQUALITY: SELF-INTEREST AND FAIRNESS}

Classic economic theories as well as early philosophical accounts assumed that people in social dilemmas are primarily motivated by their selfinterest. According to the self-interested or rationalistic approach, people's behavior in social dilemmas is guided by the expected utility of their decisions (e.g., Carpenter, 2003). This view holds that people are mainly concerned with satisfying their direct personal interest (e.g., Luce and Raiffa, 
1957). Although game theoretical approaches form the central assumption in classic economics to explain people's behavior in mixed-motive situations, and represent the position that people also may be motivated by personal gratification only, it should be noted that people also are concerned about motives other than self-interest. As David Messick (1999a, p. 15) pointed out: "I think our responses in these situations are often rooted in shallow rules, habitual rituals, and other processes that are not directly intended to maximize outcomes, values, or utilities." This position seems often to be ignored in economic theories (Rabin, 1993).

This suggests that people's motives are not only self-interested and rational, in a way that people are on a continuous search to increase their happiness and pleasure (Edney, 1980; Konow, 2003), but also that people care for social justice (see e.g., Marwell and Ames, 1979; Mitchell et al. 1993). This perspective therefore implies that the use of equality can be traced back to more than furthering one's own interest. In early philosophy, Aristotle (1998) already noticed that not only self-interest but also justice concerns matter in situations that we now refer to as mixed-motive situations. He argued that people compare themselves to others in the proportion between what they received and what they invested or contributed, which parallels insights of equity theory (Adams, 1965). That is, when it is clear that there is a discrepancy in the proportion between what one gets relative to one's contributions and what someone else is getting relative to his or her contributions (i.e., inequity), people may feel deprived and perceive to be treated unjustly (Adams, 1965; Messick and Sentis, 1983). This issue of receiving just outcomes is often referred to as distributive justice (Homans, 1961; Deutsch, 1985).

\section{TACIT COORDINATION, SELF-INTEREST AND FAIRNESS}

The fact that people care for distributive justice may indeed be an important motive for using the equality rule. Social dilemma research showed that people anchor their decisions in these symmetric public good dilemma situations (which hold that the collective outcomes will be distributed equally) on an equality rule (e.g. Allison and Messick, 1990; Marwell and Ames, 1979; Van Dijk and Wilke, 1993; 1995; 2000). Hence, people tacitly coordinate their decision behavior in such a way that they contribute an equal share to the public good. The use of equality is often represented as a focal point (Schelling, 1980). The issue of focal points can be traced back to Hume (1739/1992, Part II, Section iii), who noted the example of a Frenchman, a Spaniard, and a German who come across three bottles of wine, namely Rhenish, Burgundy, and Port, and have a quarrel about it. There are 27 ways of allocating these bottles, but Hume argued that 
the focal point in dividing the bottles is to give each nationality the wine that is related to his own country. Hence, people make use of such focal rules, as the equality rule, to tacitly coordinate their behavior.

However, the fact that people tacitly coordinate their decisions by using the equality rule does not clarify under which conditions the equality rule is perceived as an efficiency or fairness rule. Psychological research on the equality rule, for example, defined this rule as an efficient decision heuristic which is simple, easy to apply, and easily justifiable to others (Allison and Messick, 1990; Messick and Schell, 1992). Allison et al. (1992) for example, showed that when the group size increased participants were more frequently deviating from the equality rule in their decisions. Thus, when the situation to which this rule applies becomes more complicated, people seem to deviate more from using the equality rule. From this, these researchers concluded that the equality rule is an efficiency rule on which people can base their decisions, but when the situation gets more complex deviations will be more likely, because the rule becomes less clear.

In addition to being an efficient rule, the equality rule may also resemble a fairness rule, which is defined as a representation of what is fair for people to do. This is consistent with the idea that equality "represents a desire to create positive interpersonal relationships, trying to keep everybody happy and pleased" (Sampson, 1975, p. 52). Equality is related to community issues, as meant by fostering positive and enjoyable social relations and increasing solidarity (Tyler and Belliveau, 1995; see also Deutsch, 1975; Loewenstein et al. 1989; Lutz, 2001; Mikula, 1980).

The idea of equality as a fairness rule can even be found in the animal world. Research of Brosnan and De Waal (2003), for example, showed that primates refused to exchange a token for a piece of fruit and reacted very negatively when they saw a counterpart getting a more appreciated piece of fruit, and consequently, getting a better deal. Hence, this suggests that even primates perceive equality as a representation of true fairness. This is also in line with the fact that people judge the fairness of their outcomes to a certain referent standard (Cropanzano and Ambrose, 2001), and evaluate the outcomes that they receive according to whether it is fair (Tyler and Dawes, 1993). Finally, John Rawls made a similar argument (1971/1999) when stating that "the conduct of individuals guided by their rational plans should be coordinated as far as possible to achieve results which although not intended or perhaps even foreseen by them are nevertheless the best ones from the standpoint of social justice" (p. 49). Thus, fairness issues should be deeply felt when engaging in decisions to serve the collective or personal interests.

Until now, experimental evidence has been lacking about the conditions under which (or which individuals) people primarily use the equality rule out of fairness or out of efficiency concerns. This may be due to the fact that both concerns may often go hand in hand, making it difficult to disentangle 
both motives. As we will argue and demonstrate, however, it is possible to disentangle both motives by focusing on how people react when they learn another group member does not follow the equality rule by contributing less than an equal share. Depending on the specific motive that they pursue people may react emotionally upon the situation of equality violation. If people's main motive for equality is fairness then they are likely to be upset about a violation of equality. In addition, people whose primary motive is efficiency will also be upset about an equality violation because it restrains their self-interest. However, when it becomes clear that their self-interest is not affected, people who hold an efficiency perspective of equality might not be so upset any more. In the following paragraphs we will further elaborate on this issue.

\section{EMOTIONS UNCOVERING FAIRNESS OR EFFICIENCY MOTIVES}

Emotional reactions can be defined as evaluations of persons or events, which consist of such components as the appraisal of the emotion, the phenomenological experience, action-tendencies, and behavioral actions. A theory that is appropriate for describing the emergence of different emotions is appraisal theory (Scherer, 1999). Appraisal theory states that an evaluation of certain predefined factors (such as whether the event is caused by a circumstance or a person, or whether the event is rewarding or punishing, see also Roseman, 1991) determines which emotion will be particularly relevant in the given circumstances. For example, anger may be instigated by an unwanted outcome elicited by an unexpected event for which another person is to blame (Smith and Ellsworth, 1985). In addition, anger generally emerges when accepted social norms are violated or when there is disapproval of someone's blameworthy action (Shaver, 1985). Thus, the emergence of emotions is dependent on cognitively rich mental states.

Also, Aristotle referred to emotions as $\prod \dot{\alpha} \theta \eta$ (passion) which means "to suffer." He argued that emotions are evaluative states that register what is valued. When something results in pain, we speak of emotions because what we value is violated. In related terms, Aristotle argued that emotions are interrelated to moral motives. This suggests that emotions are closely related to issues of morality and fairness (Leventhal et al., 1980) because people evaluate certain conditions according to their personal goals. Further, from the relationship between the situation at hand and the extent to which one's goals are fulfilled emotional reactions may arise. Therefore, if people's main motives are violated they react emotionally and become upset. In light of this perspective, we argue that emotional reactions to violations of the equality rule can help us identify the motives that people have for using the equality rule. 
In their research, Stouten et al. (2005a) showed that emotional reactions are important to disentangle the motives for using the equality rule in social dilemma situations. More specifically, Stouten et al. first reasoned that when people use the equality rule themselves (see e.g., Messick, 1993; Van Dijk and Wilke, 2000), they may expect others to use equality as well. In addition, because people are likely to expect others to use equality, decision makers may be emotionally sensitive to violations. Note that emotional reactions may be a better measure to signal reactions to equality violation than simply looking at how others react in terms of their contributions to the public good. Indeed, research has argued and demonstrated that in symmetric social dilemmas the equality rule is such a strong and salient rule to follow that across different contribution sessions people within groups hardly deviate from equality themselves (while at the same time still experiencing different emotional reactions; see Stouten et al., 2005b). In contrast, people's emotional reactions signal when their personal goals are violated. For example, when peoples' main goal is self-interest, they are more likely to be upset when their own outcomes are reduced as a result of an equality violation.

Participants were informed that one group member contributed less than an equal share, thereby violating the equality rule. This resulted in the failure of the group in obtaining the public good (as everyone else focused on the equality rule). Because of the group's failure group members are expected to react equally negatively. Hence, because both a violation of an efficiency and a fairness motive result in negative emotions it is not possible to identify why people react. On the other hand, if the group would be successful in obtaining the public good and financial interests are satisfied, from an efficiency perspective, there should be no need to emotionally react upon the equality violation because self-interest concerns are satisfied. Yet, if group members still experience negative emotions when the group is successful in obtaining the public good although one group member violated equality, it can be argued that a violation of equality not only represents a violation of instrumental interests, but also a violation of fairness.

Indeed, using a fairness perspective, an equality violation has been suggested to result in feelings of distress (Adams, 1965), because appraisals of "justice, moral value, or legitimacy are important in generating emotions such as anger" (Roseman, 1991, p. 166; see also Mikula et al., 1998). Thus, feelings of injustice in social-decision making are characterized by being upset and reacting emotionally (e.g., Loewenstein and Lerner, 2002; Weiss et al., 1999), because it primarily communicates information about the ongoing interaction like, for example, not following an equality rule (cf. Nesse, 1990). However, if the equality rule is used out of efficiency concerns, when self-interest is satisfied negative reactions should not be expected to emerge. 
However, both efficiency and fairness motives may underlie the use of equality. That is, depending on individual differences, some people may interpret the equality rule more in terms of efficiency concerns, whereas others may interpret equality more in terms of fairness concerns. One typical individual difference variable reflecting this difference in motives is social value orientation (Van Lange, 1999). Hence, people's social value orientation could be an important variable in investigating the different motives behind the use of equality. Social value orientation can be defined as an individual difference variable reflecting how people allocate outcomes between self and other. Three main categories can be distinguished. First of all, the prosocials or cooperators assign more weight to both own and other's outcomes and equality. Second, individualists assign more weight to own outcomes regardless of other outcomes. Finally, competitors assign more weight to the relative difference between own and other's outcomes (Van Lange, 1999). Individualists and competitors are often referred to as proselfs. Because proselfs focus more on their own outcomes, they may be expected to react to a violation of equality because of efficiency, that is, because self-interested concerns are violated.

\section{EXAMINING EQUALITY AS AN INSTANCE OF FAIRNESS OR EFFICIENCY}

In their research, Stouten et al. (2005a) asked participants to play a step-level public good dilemma game, in which all group members received an equal endowment. Further, when a certain threshold of contributions was surpassed the group would earn a bonus, which could be equally divided among all group members. After participants in this game were given the opportunity to contribute to the public good they were informed that one group member violated the equality rule by contributing less than an equal share. Because everyone in the group would receive an equal part of the group bonus, the equality rule was the main focal point for people's decisions. The fact that one group member violated the equality rule thus led to the failure of the group in providing the public good (i.e., since most people stuck to the use of equality, failure by one group member to do so would result in collective failure). However, half of the participants learned that, although the contributions fell short, the public good would be provided after all and what first seemed to be a failure turned out to be a success.

In line with our argument described above, the results of two studies indeed showed that proselfs' emotional reactions toward the violation of equality were strongly dependent on the failure or the success of the group in obtaining the public good. That is, proselfs reacted more negatively and less 
positively when the group failed in obtaining the bonus relative to when the group succeeded in obtaining the bonus. However, prosocials overall displayed negative emotions irrespective of outcome feedback. Moreover, the emergence of emotional reactions was mediated by the perceived unfairness of the event. Hence, these results provide evidence that prosocials perceived the violation of the equality rule more as a violation of fairness, whereas proselfs interpreted this violation more in terms of efficiency, proclaiming the view that "all is well that ends well."

\section{WHY WAS EQUALITY VIOLATED? EXPLAINING EQUALITY VIOLATIONS}

To summarize, so far the equality rule seems to touch an important personal value, suggesting that it is also related to moral virtues. If this is true, then a violation of equality should instigate questions about why a group member decided to violate the equality rule. This line of reasoning holds the assumption that if the violator would be able to explain his/her behavior, then negative emotional reactions could be softened. However, this should only be true if the explanation proves that the violator did not show this negative behavior intentionally. If the violator's action could be attributed to the violator personally, then reactions would be particularly negative. In addition, even if the explanation did not express personal responsibility then it still would be an issue of whether group members would believe and trust the explanation. Thus, trusting others should also play a role. Therefore, the potential effect of explanations on emotional reactions should be most important for group members who express high trust in others, because they expect benign intent from others (De Cremer et al., 2001; Ring and Van De Ven, 1994) and should evaluate the given explanation as honest and trustworthy.

Thus, group members' emotional reactions may be influenced by the given explanation of the perpetrator. Interestingly, it has also been argued that emotional reactions may not only signal the intrinsic values that are violated (as we have illustrated earlier; see Stouten et al., 2005a), but they may also instigate further negative behavior, and more precisely, retributive actions (Goldberg et al., 1999; Smith, 2002). The finding that people are willing to take retributive actions can be attributed to the fact that they want people to give their just deserts (Bies and Tripp, 1996; Carlsmith et al., 2002; Darley and Pittman, 2003). Acting out these retributive actions is especially relevant when the personal responsibility of the perpetrator is known. Hence, when the violator's actions can be internally attributed (i.e., the violator is personally responsible) people can be expected to react more negatively, and as a consequence of this, use more retributive actions than 
when the actions can be externally attributed (the violation is due to external circumstances). Thus, the potential effect of explaining why equality is violated should not only influence emotions but also retributive actions.

In three experimental studies, Stouten et al. (2006) set out to answer these questions. In these studies, the same procedure was used as in Stouten et al. (2005a). That is, in a public good dilemma, one other group member violated the equality rule, whereas the others (i.e., the participants) used this rule. Before participants played the dilemma game, trust was either assessed (Study 1) or manipulated (Study 2 and 3). After it was known that a group member violated the equality rule, participants could ask for an explanation. The attribution was manipulated so that participants received either an internal (i.e., it was his own decision) or an external explanation (i.e., it was situationally caused). These studies showed that an explanation given for the violation of equality (and thus pointing out the violator's responsibility) especially influenced high trusters' emotional reactions. More precisely, when the perpetrator attributed the violation internally, high trusters reacted more negatively than when the action was attributed externally. In addition, this information did not influence low trusters' reactions. Interestingly, a third experiment added another important attribute of giving an explanation. The honesty of the explanation that is given is especially important for people's perception of the trustworthiness of the violator. The results indeed showed that high trusters displayed more negative emotions and they were more inclined to take retributive actions (e.g., excluding the violator from the group or financially punishing the perpetrator) when the externally attributed information was a lie than when it was honest. Moreover, when the information was dishonest, the attribution of the explanation did not matter in affecting high trusters' reactions, whereas it did influence emotional and retributive reactions when the explanation was honest. Especially important is the fact that the expression of these retributive actions were mediated by the negative emotional reactions that participants experienced. Hence, negative emotions (as a function of equality violation) were shown to instigate further retributive actions in social dilemma situations.

Interestingly, these results may serve as an important modification of Darley and Pittman's model (2003), which showed that emotional expressions might differ as a result of the type of attribution that is given. For example, these researchers argued that intentional harm might lead to high moral emotions and retributive actions. However, information that the violation was negligent leads to low moral emotions and compensation. Our results point out that the influence of attribution on people's emotions and retributive actions is a function of the amount of trust people have. Hence, because of this, it is possible that Darley and Pittman's statements that the type of attribution leads to different moral emotions and actions may only be important for high trusters. 


\section{MANAGING EQUALITY VIOLATIONS}

Taken together, the findings of all these studies point out the important role that emotions play in finding out why people react to equality violations and how and when they actually do this. The findings of these studies are presented in Figure 1, and thus illustrate the possible consequences of a violation of the equality rule in social dilemmas. Figure 1 describes the different stages that people go through when equality is violated. First of all, when equality is violated people will be emotionally upset. However, people may be upset for different reasons. If people care for equality out of fairness concerns, they will remain equally upset when instrumental or outcome needs are satisfied or when outcome needs are not satisfied. If equality is

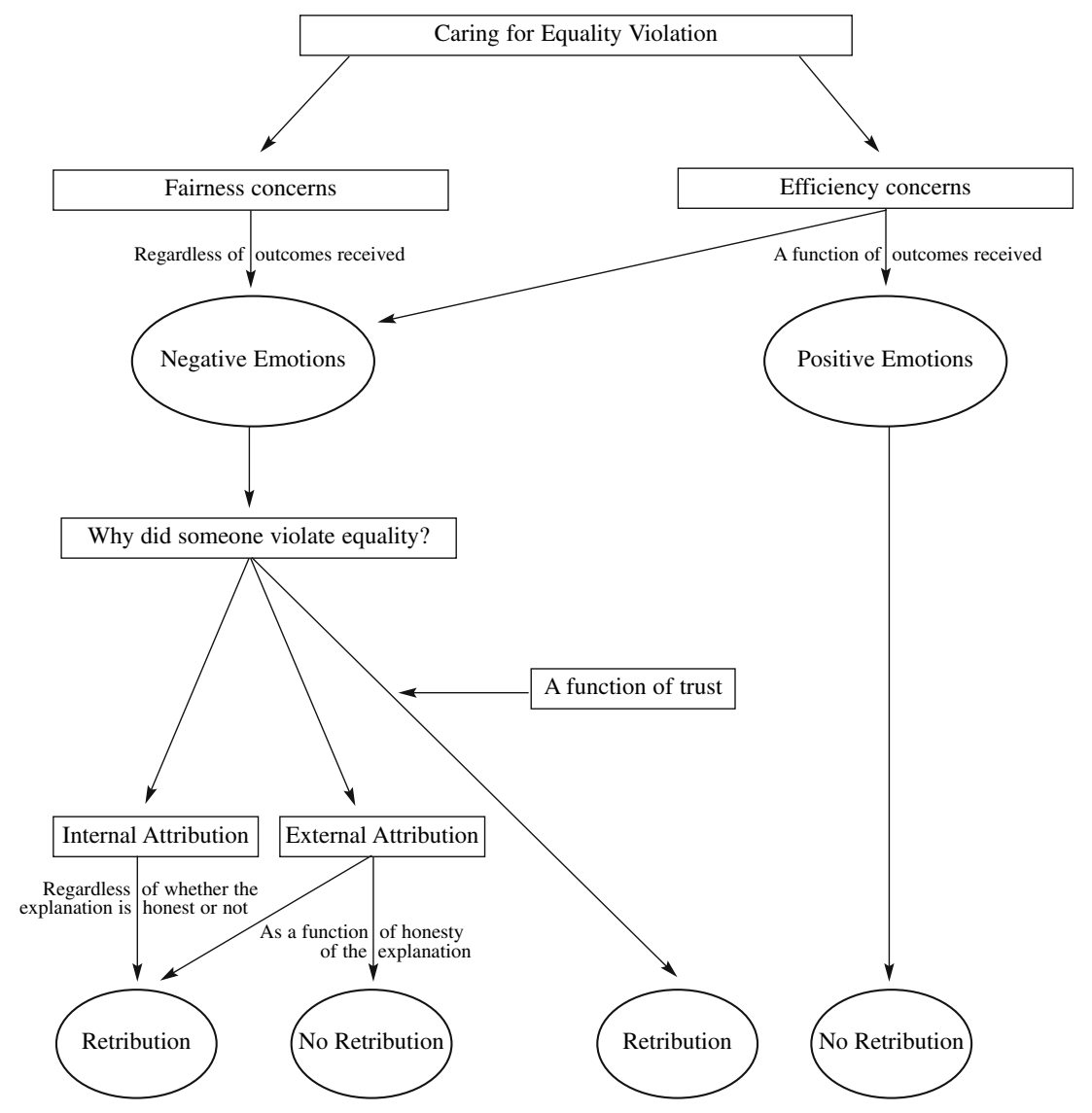

Fig. 1. Managing equality in social dilemmas. 
primarily used out of efficiency reasons, emotional reactions will be influenced more by whether or not financial gains are satisfied. Then, people will react negatively when outcome concerns are not satisfied and positively when personal interests are satisfied.

Further, Figure 1 shows that when people perceive an equality violation as fundamentally unfair and react negatively, questions about the cause of this action will emerge. Information concerning the attribution of the equality violation may or may not give rise to further retributive actions depending on the level of trust people have. However, when people see the equality violation more in terms of efficiency, and own outcomes are satisfied (and people will react positively) they are not expected to take further retributive actions.

These retributive actions, such as excluding or punishing someone are an expression of people's perception that trust is violated. Interestingly, in the Grounding for the Metaphysics of Morals, Immanuel Kant (1785/1983) noted that when trust is violated, an essential basis for cooperation is violated, but more importantly, respect for the other is lost. This issue of losing respect for the other seems to be reflected in people's decisions to engage in retributive measures in order to avenge the harm done when the personal responsibility of the perpetrator is known or when the violator's pledged not to be personally responsible and that this promise turned out to be a lie. When the violator is able to give a legitimate (and honest) explanation for the harm done no further retributive actions can be expected. However, when it is known that this explanation is based on dishonest information people are likely to turn to retributive measures. One may conclude that the violation of equality generally results in a dispute among group members. Informational resources may eventually relieve this conflict, but only if the information is perceived as honest (cf. Lind, 1997). Finally, for people who have low general trust, giving an explanation does not influence how they will react. Indeed, low trusters generally tend to use more retributive measures irrespective of given explanations.

Figure 1 shows that the equality rule, in addition to being an efficient rule, resembles an important fairness norm which elicits emotional reactions when a group member violates this rule. This was even found irrespective of financial outcomes (Stouten et al., 2005a) because these emotional reactions touch upon the fact that fairness is violated and important personal values are implicated. Because these emotional reactions signal what is valued they have the ability to communicate the motives of individual decision makers, that is, the emotional expression of a fairness or an efficiency violation. In addition, these emotions may eventually grow into the establishment of further actions, such as retributive actions. The mere presence of being emotionally aroused instigates such actions as taking revenge or punishing behavior. Hence, the violation of the equality rule eventually may lead to 
consequences that eventually lead to detrimental actions for the group as a whole.

\section{EQUALITY AS FAIRNESS}

To conclude, these findings show that the equality rule also represents instances of fairness, which group members consider to be important for the group's climate, and in turn, enable positive intragroup relationships that are generally free of retributive conflicts. This conclusion also implies that because equality is related to true fairness, adherence to equality creates a sense of community and belongingness (Cropanzano and Ambrose, 2001; De Cremer, 2002), which takes care of keeping emotional reactions well balanced.

However, as we have shown in our studies, the emotional and retributive reactions are clearly a function of the interaction between situation and personality. That is, in the studies presented the prominent influence of coordination rules is dictated by a dynamic interplay between situational and personality variables. In our view, these individual differences are important for how people perceive a particular situation, that is to which aspects of the situation they are more sensitive to. These different sensitivities in turn explain the different reactions that people may express. In the present research, these individual differences represent the extent to which people focus on, for example, morality or fairness issues (see also Leventhal et al., 1980). Future research should focus more on the interplay between situational and dispositional influences on people's reactions to justice violations. The inclusion of personality variables in justice literature has the potential to present a more complete picture of why it is that people may react differently while being in the same situation.

It should be emphasized that, in general, social dilemma research has suggested that the equality rule represents a fundamental issue of fairness and should influence the relationship within the group on moral dimensions such as emotions and retributive behavior (Eek et al., 2001; Van Dijk and Wilke, 2000), although experimental evidence for this line of reasoning was nonexistent. The experimental studies described in the present paper support these arguments, and are thus among the first to experimentally show the emergence and influence of emotional and retributive reactions in social dilemmas. The fact that emotional reactions played a significant role in justice violations in social dilemmas by identifying the underlying motives and instigating specific actions shows that emotions in these kinds of situations are an important influence. This influence is especially noticeable when these emotions arouse retributive actions. Therefore, more research is needed on emotions and retributive reactions in mixed-motive situations. 
These results are also interesting in the light of notions from economics, law, and philosophy. The fact that people apply equality and react against its violation is, for example, complementary to fundamental economic propositions that people are primarily motivated to follow self-interest. In addition to the motive of self-interest, fairness issues are also important motivations. Violating equality instigates emotional reactions in people, albeit for different reasons. Eventually these emotional reactions may lead to such detrimental behavior as retributive actions, in which both the group and the one giving the just desert are worse off.

\section{REFERENCES}

Adams, J. S. (1965). Inequity in social exchange. In Berkowitz, L. (ed.), Advances in Experimental Social Psychology, Academic Press, New York, pp. 267-299.

Allison, S. T., McQueen, L. R., and Schaerfl, L. M. (1992). Social decision making processes and the equal partitionment of shared resources. J. Exp. Social Psychol., 28, $23-42$.

Allison, S. T., and Messick, D. M. (1990). Social decision heuristics in the use of shared resources. J. Behav. Decision Making, 3, 195-204.

Aristotle. (1998). Nicomachean Ethics: Books VIII and IX (M. Pakaluk, Trans.). Oxford: Clarendon Press.

Bies, R. J., and Tripp, T. M. (1996). Beyond distrust; "Getting even" and the need for revenge. In Kramer, R. M. and Tyler, T. R. (eds.), Trust in Organizations. Frontiers of Theory and Research, Sage Publications, California, pp. 246-260.

Brosnan, S. F., and De Waal, F. B. M (2003). Monkeys reject unequal pay. Nature, 425, 297-299.

Carlsmith, K. M., Darley, J. M., and Robinson, P. H (2002). Why do we punish? Deterrence and just deserts as motives for punishment. J. Personality Social Psychol., 83, 284-299.

Carpenter, J. P. (2003). Is fairness used instrumentally? Evidence from sequential bargaining. $J$. Economic Psychol., 24, 467-489.

Cropanzano, R., and Ambrose, M. L. (2001). Procedural and distributive justice are more similar than you think: A monistic perspective and a research agenda. In Greenberg, J. and Cropanzano, R. (eds.), Advances in Organizational Justice, Stanford University Press, Stanford CA, pp. 119-151.

Darley, J. M., and Pittman, T. S. (2003). The psychology of compensatory and retributive justice. Personality Social Psychol. Rev., 7, 324-336.

Dawes, R. M. (1980). Social dilemmas. Ann. Rev. Psychol., 31, 169-193.

De Cremer, D. (2002). The self-relevant implications of distribution rules: When self-esteem and acceptance are influenced by violations of the equity rule. Social Justice Res., 15, 327-339.

De Cremer, D., Snyder, M., and Dewitte, S. (2001). The less I trust, the less I contribute (or not)? The effects of trust, accountability and self-monitoring in social dilemmas. European J. Social Psychol., 31, 93-107.

Deutsch, M. (1975). Equity, equality, and need: What determines which value will be used as the basis of distributive justice?. J. Social Issues, 31, 37-149.

Deutsch, M. (1985). Distributive Justice, New Haven/London: Yale University Press.

Edney, J. J. (1980). The commons problem: Alternative perspectives. Am. Psy., 35, 131-150.

Eek, D., Biel, A., and Gärling, T. (2001). Cooperation in asymmetric social dilemmas when equality is perceived as unfair. J.Appl. Social Psychol., 31, 649-666.

Goldberg, J. H., Lerner, J. S., and Tetlock, P. E (1999). Rage and reason: The psychology of the intuitive prosecutor. Eur. J. Social Psychol., 29, 781-795.

Homans, G. C. (1961). Social Behavior: Its Elementary Forms, New York: Harcourt, Brace and World.

Hume, D., (1739/1992). Treatise of Human Nature. Buffalo: Prometheus Books. 
Komorita, S. S., and Parks, C. D. (1994). Social Dilemmas, Dubuque, IA: Brown \& Benchmark. Konow, J. (2003). Which is the fairest one of all?: A positive analysis of justice theories. $J$. Economic Literature, 41, 1188-1239.

Leventhal, G. S., Karuza, J. Jr, and Fry, W. R. (1980). Beyond fairness: A theory of allocation preferences. In Mikula (ed.), Justice and Social Interaction, Springer-Verlag, New York.

Lind, E. A. (1997). Litigation and claiming in organizations: Antisocial behavior or quest for justice?. In Giacalone (ed.), Antisocial Behavior In Organizations, Sage, Thousand Oaks, pp. $150-171$.

Loewenstein, G. F., and Lerner, J. S. (2002). The role of affect in decision making. In Davidson, R. J., Scherer, K. R. and Goldsmith, H. H. (eds.), The Handbook of Affective Sciences, University Press, Oxford, English, pp. 619-642.

Loewenstein, G. F., Thompson, L., and Bazerman, M. H. (1989). Social utility and decision making in interpersonal contexts. J. Personality Social Psychol., 57, 426-441.

Luce, R. D., and Raiffa (1957). Games and Decisions, New York: John Wiley \& Sons.

Lutz, M. A. (2001). On the norm of equality. Int. J. Social Econ., 28, 782-799.

Marwell, G., and Ames, R. E. (1979). Experiments on the provision of public goods, I: Resources, interest, group size, and the free-rider problem. Am. J. Sociol., 84, 1335-1360.

Messick, D.M. (1993). Equality as a decision heuristic. In Mellers B.A., Baron J. (Eds), Psychological Perspectives on Justice: Theory and Applications. Cambridge Series on Judgment and Decision Making, Cambridge University Press, New York, NY, US, pp. 1131.

Messick, D. M. (1999a). Alternative logics for decision making in social settings. J. Economic Behav. Organ., 39, 11-28.

Messick, D. M., and Schell, T. (1992). Evidence for an equality heuristic in social decision making. Acta Psychologica, 80, 311-323.

Messick, D. M., and Sentis, K. P. (1983). Fairness, preference, and fairness biases. In Messick, D. M. and Cook, K. S. (eds.), Equity Theory: Psychological and Sociological Perspectives, Praeger, New York.

Mikula, G. (1980). On the role of justice in allocation decisions. In Mikula, G. (ed.), Justice and Social Interaction, Springer-Verlag, New York, pp. 127-165.

Mikula, G., Scherer, K. R., and Athenstaedt, U. (1998). The role of injustice in the elicitation of differential emotional reactions. Personality Social Psychol. Bull., 24, 769-783.

Mitchell, G., Tetlock, P. E., Mellers, B. A., and Ordóñez, L. D. (1993). Judgments of social justice: Compromises between equality and efficiency. J. Personality Social Psychol., 65, 629-639.

Nesse, R. M. (1990). Evolutionary explanations of emotions. Human Nature, 1, 261-289.

Rabin, M. (1993). Incorporating fairness into game theory and economics. The Am. Economic Rev., 83, 1281-1302.

Rawls, J. (1971/1999). A theory of justice. Oxford: University Press.

Ring, P. S., and Van de Ven, A. H. (1994). Developmental processes of cooperative interorganizational relationships. Acad. Manage. Rev., 19, 90-118.

Roseman, I. J. (1991). Appraisal determinants of discrete emotions. Cognition and Emotion, 5, 161-200.

Sampson, E. E. (1975). On justice as equality. J. Social Issues, 31, 45-64.

Schelling, T. C. (1980). The strategy of conflict, Cambridge: Harvard University.

Scherer, K. R. (1999). Appraisal theory. In Dalgleish, T. and Power, M.J. (eds.), Handbook of Cognition and Emotion, John Wiley and Sons, Chichester, pp. 637-663.

Shaver, K. G. (1985). The attribution of blame; Causality, responsibility, and blameworthiness, New York: Springer-Verlag.

Smith, C. A., and Ellsworth, P. C. (1985). Patterns of cognitive appraisal in emotion. $J$. Personality Social Psychol., 48, 813-838.

Smith, H. J. (2002). Thinking about deservingness. Social Justice Res., 15, 409-422.

Stouten, J., De Cremer, D., and Van Dijk, E. (2005a). All is well that ends well, at least for proselfs: Emotional reactions to equality violation as a function of social value orientation. Eur. J.Social Psychol., 35, 767-783. 
Stouten, J., De Cremer, D., \& Van Dijk, E. (2005b). (In)tolerance for equality violation: When violations of equality in social dilemmas affect contribution decisions. Manuscript submitted for publication.

Stouten, J., De Cremer, D., and Van Dijk, E. (2006). Violating equality in social dilemmas: Emotional and retributive reactions as a function of trust, attribution, and sincerity. Personality and Social Psychol. Bull., 32, 894-906.

Tyler, T. R., and Belliveau, M. A. (1995). Tradeoffs in justice principles: Definitions of fairness. In Bunker, B. B. and Rubin, J. Z. (eds.), Conflict, Cooperation, and Justice: Essays Inspired by the Work of Morton Deutsch The Jossey Bass Management Series and the Jossey Bass Conflict Resolution Series, Jossey-Bass/Pfeiffer, San Francisco CA US, pp. 291-314.

Tyler, T., and Dawes, R. M. (1993). Fairness in groups: Comparing the self-interest and social identity perspectives. In Mellers, B. and Baron, J. (eds.), Psychological Perspectives on Justice: Theory and Applications, Cambridge University Press, New York, pp. 87-108.

Van Dijk, E., and Wilke, H. (1993). Differential interests, equity, and public good provision. $J$. Experimental Social Psychol., 29, 1-16.

Van Dijk, E., and Wilke, H. (1995). Coordination rules in asymmetric social dilemmas: A comparison between public good dilemmas and resource dilemmas. J. Experimental Social Psychol., 31, 1-27.

Van Dijk, E., and Wilke, H. (2000). Decision-induced focusing in social dilemmas: Give-some, keep-some, take-some, and leave-some dilemmas. J. Personality Social Psychol., 78, 92-104.

Van Lange, P. A. M. (1999). The pursuit of joint outcomes and equality in outcomes: An integrative model of social value orientation. J. Personality Social Psychol., 77, 337-349.

Weiss, H. M., Suckow, K., and Cropanzano, R. (1999). Effects of justice conditions on discrete emotions. J. Appl. Psychol., 84, 786-794. 